\title{
Noticia para la Antibiografía de Leonidas Yerovi.
}

\section{YEROVI, PERSONAJE NOVELABLE}

Vida improvisada y vehemente la de Yerovi, condiciona un porvenir que él mismo no entreveía tan claro. Su misma vehemencia le impidió detenerse a pensar, en su presente intenso o en un futuro inmediato $y$ sorpresivo. Lejos de sorprender la muerte a Yerovi, él es el que sorprende a la muerte, recibiéndola tal como siempre lo hubiera querido, entre un poema frustrado y unas fiestas próximas de Carnaval; entre la mesá del latredacción y calle limeña por antonomasia, el jirón de da Unión, como una exaltada médula espinal de la ciudad. Y la recibe cuando la muerte no tenía nada que arrebatarle, más que unos años de juventud, que él había vivido ya con antelación impaciente y con largueza. Porque la figura de Yerovi se destaca sobre un generoso fondo de dilapidación. Dilapidación pródiga e integra, de los que hubieran podido ser sus más esquivos ahorros humanos. Todo corazón, dinamismo y generosidad, cruza la vida este bohemio adelantándose a su propio ritmo. Talento e imaginación, diario derroche con que decoraba el hora- rio exigido-de su cariño. Su cariño: uno y múltiple al que llegó siempre con atraso, o por el contrario con un terrible adelanto, y que forjó la viñeta más melancólica de su propia 
novela: Aquí en el Perú, el país por excelencia de un largo contenido emocional. Emoción telúrica y emoción humana, como dos enormes fuerzas sin cauce en compaz de espera, de una lograda creación constructiva. Aquí, donde tenemos la urgencia de hablar de personajes novelables, antes que de una novela que sólo está en promisora aunque vigorosa pubertad. En un largo índice tendremos que agrupar a Leonidas Yerovi junto a la Mariscala. Muy junto a ella Valdelomar-el casi su creador-A su vera Santa Rosa de Lima, Ramón Castilla y tantos otros. Afirmación de un selecto perfilarse humano de agudísimas proyecciones para su realización novelada. Hoy ya se puede tener ciega confianza en un futuro novelado del Perú, hecho de su propia riqueza inminente y vital. Junto a la novela de pura imaginación creativa tan apreciable y cabal, pero que en el Perú todavía no ha llegado a solucionarse en una dirección definitiva, tendrá que aparecer maduramente amanecido nuestro porvenir, en los caminos a que claramente la delata su futuro discurrir. De un lado, la expresión rural de nuestra novela campesina, que ya constituye hoy día una palpitante realidad de morfologia propia y paisajes inconfundibles, que alientan su desarrolfor. Expresion de una expectativa $y$ un presente inmediato que nadie se atrevería a dudar, ni a disentir. Intimamente ligada con algunas modalidades de la anterior-poseedora de una función humana conún-propende a desarrollarse y crecer, el ámbito literario de la novela racial con un contenido de emoción inconfundible. País de mestizaje y campesino, el Perú tiene que dar una humana solución a su doble tensión social. Y junto a ellas el con-. solado optimismo que haga revivir entre el mundo asediado de la creación latente, la dúctil riqueza novelada que es todavía una promesa en espera. Volver hacia las vidas para lograr el milagro de una post-vida más emocionante y nue- 
va-o igualmente emocionante e inédita-. Aquí donde no se puede hablar del acerbo de nuestra novela, sí podemos en combio hablar con generosa despreocupación de nuestros personajes novelables, de cuatro siglos transcurridos bajo las temperaturas espirituales y sociales.

Leonidas Yerovi es una de las más exactas posibilidades para esta empresa matinal. Tiene toda la riqueza sicológica de un criollo engreído, aventurero e inteligente. $Y$ todo el atrabiliario programa de una bohemia periodística amargamente alegre, audaz y original. Realizó la idea cabal de un tipo extravertido, de vida intensa, y como de cierta impaciente angustia que interiormente lo convenciera de la brevedad de su peripecia. Lo sabemos, como al periodista ágil, al autor afortunado, al amigo entrañable, al enamorado impenitente. En él, la familiaridad de la frase "vivir su vida" perdió toda su vulgaridad. Yerovi vivió su vida tan honda $\mathrm{y}$ tan exactamente que sorprende y desconcierta. $\mathrm{Y}$ cuando la muerte lo reclamó en forma violenta y sorpresiva, uno se queda abismado de cómo, el suceso definitivo en la vida del hombre, llegó para Yerovi en forma tan audaz y original como habiar sido sucvida. Yerovirse ganó a sí propio, viviendo y muriendo la historia, que quién sabe si a él mismo, le hubiera correspondido escribir.

\section{INADAPTACION, DESADAPTACION, BOHEMIA}

Impulsos emocionales son los que violentaron sin claudicación la vida de Yerovi. Reclaman predominio sin discusión sobre cualesquiera otros. En la encendida y álgida bohemia que significó una generación periodistica brillante, sin antecedente y-todavía, sin consecuente-la nariz de Yerovi-su interrogación civil y célebre-apunta sobre un 
derrotero inconcluso. Concluído sólo por él, brutal y trágicamente, como debía ser. Por más que él se empeñara en adoptar un gesto cívico-broma perdonable e inofensivacon que oficialmente aparecía ante la sorprendida ciudad. Unía en su personalidad en inicua hermanía, su dinamismo y su pureza, de que tanto se le acusa, de no haber terminado toda una obra en promesa. Vivió íntegro su vida. Vida sin método, sin cauce, intensa, torrentosa y aplacada. Atrabiliario, catador de un campo dúctil que se contaba a partir de las mismas entrañas de un periodismo sin descanso, y hasta los altos y reacios paraísos de una literatura entresoñada. Pero en todos los caminos sólo se supo de él, por su gesto precipitado de turista angustiado, en empedernido dilema de quedar y de irse, sin solución y sin objetivo. Entonces no queda sino una cabal constatación ineludiblemente asociada al destino de su nariz. Nariz bohemia y desadaptada entre su rostro, como él lo fué en este mundo ineludible. Perennizada en retratos y caricaturas en los que se destaca airosa y agresiva, célebre, popular e imprecisa. Disconforme como ella lo fue Yerovi en su trayecto. No sabemos si la sociedad hiere agYerovi, o si Yerovi hiere con finisima daga a su ciudad. De una manera o de otra el humorista y el lírico gozan desaforada y despreocupadamente del minuto reacio, que adivinan, además, breve. La ciudad lo tolera; más que lo tolera, lo necesita y lo quiere. Siente la imperiosa urgencia, de una liberación un poco vedada. Ríe, se duele, muere, agoniza, sueña a través de su poéta, todo el programa inimaginado que es incapaz de realizar. $Y$ el bohemio, consagra su tipo predilecto, a quien critica, pero secreta y públicamente admira. Cuando Lima oficialmente prodiga su elogio y su simpatía al poeta; su más íntima y recóndita intención, mima, y acude por el bohemio, con la frágil y golosa dulzura de lo prohibido. Su cinismo ático y 
desaprensivo, la altera y crea un profundo jardín de simpatías. Mientras su bohemio alterna alegrías y angustias en cada nuevo-y por lo mismo sorpresivo-momento: "entre sus novias y entre sus amigos, Yerovi, daba entera el alma" escribía un contemporáneo suyo. Y él sabía decirlo, un poco alegre y cínicamente, aún cuando recién empezaba su carrera literaria: "A un conquistador" era uno de sus poemas y muy ufano añadía "de colega a colega". Era la jactancia inofensiva y simpática que siempre puso a su aventura de amor; como cuando dice en "consejos interesados" (Actualidades 1904):

$$
\begin{aligned}
& \text { más si cariño tu pecho ansía } \\
& \text { y necesitas Aurora mía } \\
& \text { quien te idolatre con frenesí, } \\
& \text { quien te dedique su pensamiento } \\
& \text { quien no te olvide por un momento } \\
& \text { vuelve los ojos, cese tu llanto } \\
& \text { fíjate en mi". }
\end{aligned}
$$

Lo llamaban "el niño Yerovi" justa y cariñosamente. en vida y en muerte sus contemporaneos tuvieron palabras atildadas para admirar su gesto humano. Federico Guillermo More, lo ubica el año I9II en "Ilustración Peruana", con extraña precisión: "Desvergüenza lírica y cinismo sentimental:- dice-tal es la fórmula del espíritu de nuestro poeta". Y al mismo tiempo lo acusa de formidabies "pecados de holgazanería".

No en vano Yerovi, convicto y confeso amador, inseguro e inconstante, escribía vagos versos biográficos de calurosa delación:

Ni a los yugos más sedeños, ni en la jaula más dorada quiero verme uncido o preso bajo el cielo tentador, 
yo amo el aire crudo y libre de la pampa asoleada

yo amo el nido que improvisa la floresta perfumada

yo soy pájaro de cuenta, yo soy pájaro cantor”.

Libérrimo detentador de sus propios defectos-también de sus virtudes-lo dice con franqueza:

Vuelo, fugo... . voy al bosque donde acampo entre legiones de otros pájaros burlones que detestan la Ciudad....."

Con esa íntima condescendencia para su corazón, toma la vida en su propia dosis, lleno de conformidad y sin rebeldia:

Embeberme en la corola de cada rosa, y ahíto rodar luego, si es mi suerte, con un trino como un grito doloroso en mi garganta, pero de un eco burlón".

$\mathrm{Ni}$ la protesta encendida, ni el deliquio femenino; actitud despreocupada y familiar, hecha del mismo nervio de su libertad. No quiere que le aprisionen s"ni las manos más pulidas". Sigue un camino eportuno:rson

$$
\begin{gathered}
\text { yo soy como me han forjado } \\
\text { y no como se eligiera". }
\end{gathered}
$$

Su inconformidad social se resolvió dentro del clima intelectual de su época, en una bohemia impenitente. Compartió con Valdelomar la encarnación de este difícil tipo de espontaneidad. Pero en Valdelomar la bohemia fué más literaria que humana; mientras que en Yerovi era más humana que literaria. Lo simpatía general tuvo para él todos sus halagos y sus condescendencias porque Lima pudo entrever, todo lo afirmativo que escondía bajo su disfraz diario. "Este bohemio alegre y despreocupado-refiere Cabotin-fiel 
y sincero en la amistad, leal y generoso en el compañerismo intelectual no tenía ni enemigos, ni envidiosos". Todos sus contemporáneos hablan de su gran corazón, como una expresión raramente valiosa. Federico Larrañaga, ese otro gran bohemio de su generación, muerto prematuramente en Suiza, hace cumplido elogio de su fibra emocional: "es dueño de un carácter alegre, vive siempre en broma y tiene un corazón infantil, púber de bondades y de simpatías; un cerebro, sólido, equilibrado, frágil, elástico y preñado de armonías y de ritmos..." (Siluetas bohenias, Variedades, Igog).

Desadaptación, inadaptación, bohemia. He aquí tres de las humanas razones que hicieron vivir y morir a nuestro poeta. Tuvo el gesto noble y temerario de poner su voluntad y su talento al servicio del corazón. $\mathrm{Y}$ por eso su vida está entrecortada con los entusiasmos y los temores que se forjan en las mismas entrañas de la angustia.

\section{EL DIALOGO HUMANISIMO}

\section{Blolioteca de Letras}

"Jorge Puccinelli Converso»

Leonidas Yerovi nos depara su diálogo lleno de ternura y contradicción. Y lo realiza en su más cimera y atormentada expresión, respondiendo a una pregunta que tanto y de tan lejanas distancias sucesivas se han planteado denodadamente impacientes líricos. No trascurrió en él, esa tranquila y no sabemos si privilegiada situación de los que logran una perfecta adecuación entre su aliento interno y la expresión exterior. Esa equilibrada mesura en la que coinciden las dos fuerzas gestoras de la obra intelectual, y logran una irreparable conclusión llena de parquedad y alegría, pero a veces también ausente del enconado y alto signo que preside las obras hechas en el forcejeo vivido en la 
angustia. Tragedia, y no única en la vida de Yerovi, fué esta falta de una común medida para dos fuerzas que en su ser se trocaban en tensas y odiantes oportunidades. Cuando Yerovi percibe y logra la forma literaria-en su uniforme intelectual de "humorista"-irrumpe irreparable ese otro e inconfundible aliento interior, que toda su vida lo elevó, aquejándolo, gozándolo y persiguiéndolo en una masculina y vibrante pugna espiritual; por eso es que formal y literariamente Yerovi fué un contradictorio; un contradictorio gestado en su propia vocación, y en su terriblemente intrascendente misión. Mientras el público réía, Yerovi sufrió íntegra y logradamente su risa. Porque tras de la forma acabada e impecable, él nunca pudo detener la beligerante misión de sus impulsos interiores. Es así como su vida transcurre en medio de un acesante diálogo agitado. Diálogo que ni siquiera terminó con la pausa inesperada de su muerte, sino que deja una interrogación más sin respuesta; un otro problema, larga y dolorosa dilación inmerecida. Fué un contradictorio simultáneo, y no esos contradictorios sucesivos en el obrar, que tanto tacaecencen toda historia. Se desenvolvió en una o muy inútil g muy fecunda pugna, que luchaba por derrotar la propia contradicción, creándola en ese mismo momento, y así en toda su trayectoria humana. Iucha imposible de olvidar, porque fué la que deleitó la acongojada belleza de esos inigualables "versos del Carnaval".

"Poco se ha escrito en el Perú-ha dicho Federico More-más risueñamente pensativo". Tienen un íntimo y sincero sabor pirandeliano. Mejor pudiéramos decir, una intuición pirandeliana, en la época en que se escribieron, a principios de I9I I. En el poema se hermana a una potente y extraordinaria fuerza lírica, la ironía doliente e inagresiva, y la forma redonda y brillante. Sueño y realidad se opo- 
nen y entrecortan, mientras los protagonistas se desdoblan sobre sí mismos y varían. $Y$ la solución siempre es absurda:
¿Estaba muerto? ¿Soñaba con ella? ¿Estaba dormido?
No lo sé, ni me importaba
Pierrot estaba y no estaba
Pero yo estaba bebido...

El drama siempre se nutre de la propia entraña del absurdo. El drama lógico nunca llega, queda detenido, se asusta de su propia inminencia. E1 poeta conoce muy bien estos inseguros resortes de la realidad, y verifica un admirable malabarismo de conceptos. Resuelve la realidad por el absurdo. Y determina las lindes imprecisas del ensueño con agresiva exactitud lógica. El resultado es y tenía que ser el drama. Pero es un drama tan totalmente dramático, que al mismo tiempo es esencialmente absurdo. Le repugna precisar la atmósfera por donde trafica; sus estampas confunde dos sonidos en una misma vibracion: uno sutil, de fuga y otro terrenal. Ante esta miestra no podemos averiguar si es nuestra vigilia o nuestro sueño:

Temblando entre los espejos con luminosos reflejos los focos de las cornisas y bajo las claras ondas todo era fru-fru de blondas entre estallidos de risas, fulgor de vivas miradas encuentro de ojos traviesos diapasón de carcajadas y húmedo sonar de besos". 
Pero sí podemos decir que es un Pierrot enormemente humano, sobre todo porque es de pura ficción. Yerovi se complace- ¿o se duele?-de presentarnos tal como debe ser un anti-pierrot digno que pueda erguirse ante esa prostitución genérica a que lo han sometido los literatos:

Yacía lívidamente

y congelada en su frente

una línea de sudor

surcaba la blanca harina

que humedeció Colombina

con sus ósculos de amor

$\mathrm{Su}$ faz trasparente y seca

se transía en una mueca

estupendamente loca

y era agresiva la hueca

negrura de su ancha boca".

El poeta se encara a Pierrot y logra en una feroz arenga, convencerlỏ deeque abandone la smuerte. Y Pierrot "abandona la muerte", a través de una escena de dolor y ironía. Su movimiento se produce al recuerdo de Colombina:

$Y$ ante aquél nombre querido

ví como se levantaba.

Le ví de mi brazo asido

Pierrot estaba y no estaba

pero yo estaba bebido...".

Pero Pierrot se había adaptado a la muerte, mucho mejor qué a la vida. Por eso estos nuevos primeros pasos son inseguros y también aburridos. Yerovi constata que 
Pierrot "forcejeaba, por huir hacia el olvido". Pero el furor lo estaba acechando desde todos los rincones del salón. Oye y vé a Colombina, $y$

Pierrot vibró al escuchar

la risa de aquél reir

$y$ al ver a la infiel pasar

sintió el ansia de morir

pero $\sin$ resucitar".

El drama se posesiona de la realidad "in crescendo". El poeta hace proesas de versificación; son como sus vacaciones dentro del poema:

Luego una fuente que zumba

más tarde el zumbar de un vaso

y ya armada la querella

el tremolar de una silla

el volar de una botella

y el adiós de la vajilla

; Maravillă! Maravilla! Letras

La vigilia conspira por apoderarse del poema insoportablemente. El poeta redentor del nuevo pierrot resurecto, se enreda en una lucha de malas consecuencias:

Fué una lucha detestable

¡cuál se portó el miserable valido de su poder!

Los protagonistas emigran en un éxodo veloz y opor. tuno. Corren a refugiarse en un integérrimo limbo celestial. La afanosa creación del poeta se diluye como debía sucumbir, absurda y trágicamente. Risueñamente, agitadamente: 


\begin{abstract}
Y mientras yo desvaído, de mi suerte blasfemaba bajo el rencor del bandido ¿Pierrot estaba? ¡No estaba! ¡Pero yo estaba molido!
\end{abstract}

Pero es el drama que no concluye, que vive en su muerte en un paraíso absurdo, inconfundible e inconfundido, donde acude el poeta como a un hogar dolorido y risueño, pero donde nuevamente se ve en la duda ley de añorar la tibieza que no logra completamente. La fugáz temperatura de un sueño inconcluso, afanoso y libre, que insinúa, su ala acogedora, para inmedialamente interrumpirse en realidad. Brusca caída entre dos mundos astrales dibujados con humo y carne, ambos perecederos, precisos e incitantes, porque alientan una áspera esperanza, y que al mismo tiempo bosquejan el ancho gesto de la muerte.

\title{
SU ESCAPARATE MARAVILLOSO
}

Urgido por un destino, que apura en un ritmo intenso, no por eso Yerovi, deja de poseer líricamente un paraíso desconocido y amable, que ha forjado día a día sobre un andamiaje de sueños. No es este el mundo maravilloso que siempre se ha atribuido a Eguren-mundo difícil y difumido-un poco accesible sólo a los iniciados. Yerovi edifica su recinto maravilloso más humilde, fresco y tembloroso, como un infantil escaparate de muñequería:
'Añoro, huraño y sencillo
mi mundo, quizás mundillo
pero mi mundo interior".

Sus habitantes no contrastan con actitudes lentas, si- 
no más bien con movimientos demasiado ágiles. Allí preside él mismo, su sociedad disparatada, bajo un disfraz insistente de Pájaro Burlón, dispuesto a claudicar inevitablemente ante el sutil encanto de la "Señorita Risa" en todas las "misas de alba" de su calendario sin fin. Gusta soñar con "Madama la Luna" que cantará en musicales versos:

Esta noche la Luna bien querida ha venido a buscarme en el balcón a inundarme en su luz y darle vida de dulcísima paz a esta escondida válvula inquieta, que es mi corazón”.

De pronto se interrumpen con pausas de una deleitosa fruición. Es la "Señorita Muñeda que llega, y él rectifica razgo a razgo, con minuciosidad culpable. Para ella el poeta entona su más delicioso madrigal; un madrigal dulce e intencionado que musita a media voz para no quebrar el frágil cristal del aire. Atribuye al Sol ajenas cortesias, para su pequeña preferida:ioteca de Letras

Ella es así. Posée "Jorge Puccinelli Converso»

la belleza más cándida y más fina

de la muñeca expuesta en la vitrina

que aguarda quien la admire y la desée!

cómo será la señorita bella

que el Sol madruga sólo por su vida

y una mañana la gentil doncella

no abrió los ojos, se quedó dormida

y aquella vez no amaneció por ella".

Refiere en sueños, como la niña que lo quería tenía "la boquita de turrón" y qué: 
sus manos eran enanos

manojitos de jazmines

más que bellísimas manos".

y añade su desencanto:
pobre y dolorido amor
tronchado botón en flor
y por eso adolorido
y por eso encantador".

Siguiendo su inevitable imperativo relata una recepción encantada: las bodas del "Caballero Soneto" con la "donosa Canción". Para ellos su escaparate se vistió de las más inéditas galas:

Presidian el cortejo en la simpática boda que era toda

$$
\text { poesía, }
$$

la fresca doña Poema, la austera viuda, la Oda

$$
\begin{aligned}
& \text { y la matrona Elegia". etras } \\
& \text { "Jorge Puccinelli Converso" }
\end{aligned}
$$

Y cronista impenitente de un terrible suceso de poesía, no puede menos de anotar al día siguiente, cierta dificultad conyugal ocasionada por "el jovencito "Epigrama”, entre los flamantes esposos.

Dos damas sabrayan la transparencia de sus siluetas en los perfiles del vidrio; una es, la "Princesa Risa", y otra la "Señorita Ilusión". El cariño del poeta vacila entre ambas, las quiere y las odia a ellas con idéntico furor; y las reclama en todo momento:

Ah, la bella señorita

que llevo en el corazón 
si me olvida, Dios permita

que comparezca a su cita

la señorita Ilusión".

La quiere inseparable por ser "mínima, breve, hechicera" y porque "tiene los ojos traidores". En cambio la Princesa Risa, es voluble y parlera: y sin embargo.

Una mañanita de la primavera

la Princesa Risa despertó llorando...."

Con ella sentía de repentinas cercanías y alejamientos impensados. Una noche quiere gustar con ella "las miles que la luna derrama"; pero inesperadamente la princesa se marcha:

-Porque está cansada de soñar amores".

Así Yerovi afinca la fragilidad de un dogma maravi1loso. Crece su fe en él, como una compensación y como un descanso. $Y$ lo viste de galas tan sutilmente frágiles, que parecen fabricadas por los dedos de los ángeles.

\section{"Jorge Puccinelli Converso"}

\section{CISNEROS Y YEROVI}

Fraternalmente unidos aparecen en nuestra literatura Cisneros y Yerovi. Un mismo amor por la poesía y por esta tranquila y un poco dulce ciudad, los acerca y alienta una amistad profunda, y llena de lealtad. Coincide con la anécdota que Ricardo Palma relata en el pórtico de Poesía Lírica, libro póstumo del poeta, la aparición de la palabra literaria de Yerovi.

"Si la-memoria no me es infiel-cuenta el ilustre tradicionista-fué allá por los años de 1905 cuando ví por primera vez a Yerovi, en aquel saloncito de la Dirección de la 
Biblioteca Nacional por donde han desfilado en un lapso de cerca de seis lustros, casi todos cuantos en el Perú manejan con más o menos acierto, los trastes de escribir..... Y no pasó mucho tiempo sin que, como fruto de tales aficiones, viera con frecuencia en los periódicos, al pie de composiciones que eran prodigios de fluidez y de agudeza, la firma pronto popular y prestigiosa de Leonidas Yerovi”. Efectivamente el año de I905 ya la firma del poeta era extraordinariamente conocida en la Capital. Su "debut" le había cabido hacerlo en "Actualidades" más o menos unos dos años atrás. A partir del número I 5 de esta singularmente interesante revista limeña, se ven publicadas casi sin interrupción ingeniosa letrillas, plenas de humorismo sin violencia; y de una alta ironía sin llegar a la mordacidad. Yerovi tenía cierta predilección por el género epistolar rimado, en el que desarrollaba desconcertantemente toda una teoría de los sucesos menores que aquejaban a nuestra incipiente ciudad. Admira como en Yerovi no se produjo un proceso de perfeccionamiento ostensible en el transcurso de su obra. Fué desde el primer momento an rimadorSnatural, dotado de esa difícil disposiciôn painallograrvarconsonante oportuna, que pueda lograr el verso sin forzar la sintáxis, ni la idea. Y esa singular facilidad no fué en él fruto de una labor de aprendizaje, sino fué-por el contrario-un intuitivo de la rima, y por eso pecó antes por exceso que por defecto ell su balance lírico. Mientras Yerovi en la redacción de "Actualidades" consagraba ya a fines del año Igo3 una sección humorística bajo el atento título de "Crónica Alegre". Luis Fernán Cisneros pulía una lírica llena de transparencia y delicadeza. En el lapso que transcurre entre 1903 y I907, la-revista limeña "Actualidades", desarrolla una decisiva labor literaria, que es imposible olvidar. Mientras $\mathrm{Ye}^{-}$ rovi redactaba su Crónica Alegre, Cabotín inauguraba y 
sostenía en "Viendo Pasar las Cosas" una curiosa labor social. Luis Fernán Cisneros redactaba su sección Ex-Cátedra que después continuaría Octavio Espinoza, y en sus páginas están las firmas de toda una generación literaria peruana: Palma, Gálvee, Chocano, Aramburú, Izcue, Lora y Lora, Amézaga, Renato Morales, Beingolea, los García Calderón, Ismael Portal, Sassone, etc.

Con una labor llena de pulcritud y sobriedad "Actualidades" estuvo muy lejos de la chabacanería, y antes por el contrario significó una selecta categoría intelectual gracias al talento lleno de entusiasmo de sus animadores. Así pudieron después de traspuesto ese difícil meridiano que para 11na revista significa su número I0O, publicar una carta autógrafa de Menéndez Pidal dirigida a Cisneros, plena de conceptos elogiosos para la revista. En esta atmósfera es donde se fortalece la estrecha amistad entre los dos poetas. En el número 67 de "Actualidades" Yerovi le dedica a Cisneros unos Ensayos de Poesía Modernista "tímidamente". Nuestro ambiente intelectual atravezaba, en esa época, por una etapa insegura. Se téranas lasoesias de Amado Nervo y José A. Silva. Jrse entendiallelcmodernismo más por su modalidad meramente exterior, en lo que representaba de innovaciones en la preceptiva, que por su significado íntimo. Entonces los poetas eran leídos por el gran público y por las mujeres. Y no se había consolidado un estado de espiritu de "arte puro" que significara un divorcio entre la masa y la "élite" como ocurre en nuestros días.

En tales circunstancias es que se afinan y gestan paralelamente las dos líricas hermanadas y diferentes. Un mismo cariño a Lima pero desde dos estados de espiritu diferentes nutre y alienta las poesías de Yerovi y Luis Fernán.

Cisneros, depositario de una herencia lírica casi aristocrática-Luis Benjamín Cisneros, de Libres Alas-tiene 
un tono ceñido y delicado para cantar las virtudes de la querida ciudad. Su modulación es fina, recatada, pulida. Siente la alta ciudad, su noble genealogía, su destino de abolengo. Tan bohemio como su inseparable compañero de periodismo, reune sus versos tardíamente en un libro que titula "Todo Es Amor" como una dulce confidencia plena de romanticismo.

Luis Fernán Cisneros encarna así al poeta limeño por antonomasia. Pero su canción se dirige únicamente a la alta Lima descendiente de un pasado virreinal pleno de leyenda. Siempre ajusta la molulación de la voz para un autditorio de esperanzas femeninas. $\mathrm{Y}$ en sus págınas está la biografía de la mujer limeña afinada hasta la transparencia. Sabe cantarla aureolada de un nimbo santo y lleno de galanura, en Santa Rosa de Lima:

Hace trescientos años que el jardin florecía y lleno de perfumes florece todavía....."

A través de todósosus poenua Ise sospecha una nostalgia por todo aquello que significaba aristocracia y romance. Y al cantar a la limeña, canta a la "muñeca limeña" en lo que tiene de inmaterial y frágil:

Muñeca limeña ¡Qué bonita eres!

y cómo te quiero porque no me quieres.

¿Nó arranca tu porte

de esa ya brumosa menina de corte que un día viniera

llena de zozobras sobre la velera nao en que volcaba Felipe Segundo sus adulaciones para el nuevo mundo?" 
Y cuando canta a la colegiala limeña ¿Nó la canta a través de la "sampedrana", cifra y compendio de la descendencia de la alta alcurnia limeña?

Es por eso que Luis Fernán Cisneros es también un nostálgico como Ricardo Palma. Y su "limeñidad", desde luego que fundamental e íntegra-lo es en cuanto significaahora en campo lírico-todo el prestigio y la visión aristocrática que llega desde un "coloniaje romántico" como podría decir Angélica Palma.

No es nada parecida, en cambio, la "limeñidad" de Leonidas Yerovi, sin dejar de ser tan fundamental y concreta como la del autor de los "Daguerrotipos". Yerovi ni añora un virreynato lleno de prestancia, ni sufre la íntima emoción lírica, ante las supervivencias llenas de delicadeza de un pasado. Tiene otros ojos para ver Lima, y con ellos ve todo aquello en lo que Cisneros no repara, o gusta olvidar premeditadamente. Yerovi no es el poeta de la "Alta Lima" sino el poeta de todo aquello que no lo es; sino más bien de la "Lima baja". Mientras Cisneros revive la calle Mercaderes decorada con una solución de "muñecas" llenas de fragilidad y aristocracia, Jerovi relata cualquier cotidiana belleza quépuede ocurite en Cp Cércado o en cualquier otro lugar exento de lustre-limeño. Cisneros tiene un tono aristocrático; Yerovi una modulación familiar. Frente al adelgazamiento casi inmaterial que emplea Luis Fernán Cisneros, por ejemplo, en su poema El Amor es un Paisaje. ¿Cabe más alegre algarabía que esta dulce exclamación toda vibrada de cariño?:

Pajarita, ya lo sabes. Pajarita si eres buena no me esquives reprochando mi voluble condición. Pajarita, pajarita, pajarita es una pena, más nací como me hicieron, y nací con la condena de ser pájaro bohemio, de ser pájaro burlón. 
La diferencia es que Cisneros quiere evadirse de lo terrenal, mientras Yerovi permanece en ello. Es así como su creación de la "Princesa risa" nunca se inmaterializa totalmente, sin perder por ello una categoría de poco común excelencia lírica; igual observación podría hacerse en Mandolinata y tantos otros poemas. Porque Yerovi no desdeñó la delicadeza, sino se puede adivinar en él un profundo proceso interior, algo así como un temor de dar libre expansión a su robusto lirismo. "Suplicatoria", una de sus mejores poesías, es un modelo de sobriedad y pureza un tanto melancólica :

\section{Señora breve y pulida que buscas amor en vano y que adormeces tu vida entre la pompa florida de tu quinta de verano".}

Pero este íntimo temor a delatar una secreta ternura interior da origen al resorte de su poesía, pues acalla con una breve sonrisa, el proceso de la emoción, dejando una tenue vibración "fisueña Asin lo podeños apreciar en una de sus últimas poesias, que publicara "Variedades" a raíz. de su muerte:

me detuve en la vidriera

del lienzo en exhibición

al partir con vago anhelo

de un dulce sueño de amor

oscilé entre el paralelo

de si admirar el modelo

o si envidiar el pintor". 
Tanto Leonidas Yerovi como Luis Fernán Cisneros, han logrado una pura pasión limeña. Uno y otro respondieron a un diferente designio interior. Si Cisneros es el exacto intérprete lírico de la Lima tradicional; Yerovi lo fué de la Lima inmediata, de la Lima real. Intimamente unidos en el periodismo y en la vida, reclaman igual situación en nuestro panorama literario. Y si Yerovi sigue escribiendo su sabrosa crónica rimada, en los ámbitos que para nosotros son una última interrogación, estoy seguro que dirá su aprobación, con su más inofensiva broma.

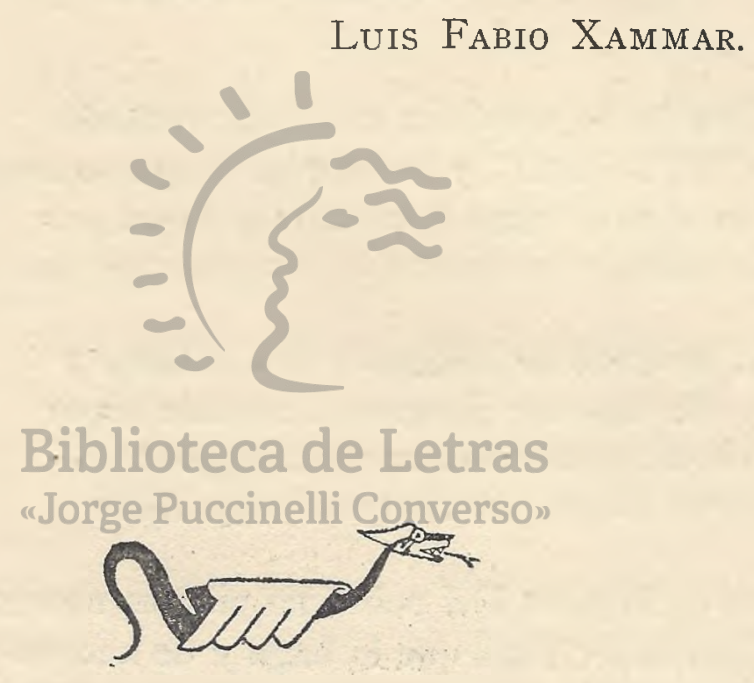

